\title{
Effect of Different Mineralization Modes on Strengthening Calcareous Sand under Simulated Seawater Conditions
}

\author{
Shiyu Liu ${ }^{1,2, *(\mathbb{D})}$, Bowen Dong ${ }^{1}$, Jin Yu ${ }^{1}$, Yanyan Cai ${ }^{1}$, Xingqian Peng ${ }^{1}$ and Xianqi Zhou ${ }^{3}$ \\ 1 Fujian Research Center for Tunneling and Urban Underground Space Engineering, Huaqiao University, \\ Xiamen 361021, China; hqudbw@stu.hqu.edu.cn (B.D.); bugyu0717@163.com (J.Y.); yycai@hqu.edu.cn (Y.C.); \\ pxq@hqu.edu.cn (X.P.) \\ 2 Key Laboratory for Intelligent Infrastructure and Monitoring of Fujian Province, Huaqiao University, \\ Xiamen 361021, China \\ 3 Institute of Technology, School of Civil Engineering and Architecture, Xiamen 361024, China; \\ xqzhou@xmut.edu.cn \\ * Correspondence: scholarrain@163.com
}

Citation: Liu, S.; Dong, B.; Yu, J.; Cai, Y.; Peng, X.; Zhou, X. Effect of Different Mineralization Modes on Strengthening Calcareous Sand under Simulated Seawater Conditions. Sustainability 2021, 13, 8265. https:// doi.org/10.3390/su13158265

Academic Editor: Castorina Silva Vieira

Received: 23 June 2021

Accepted: 21 July 2021

Published: 23 July 2021

Publisher's Note: MDPI stays neutral with regard to jurisdictional claims in published maps and institutional affiliations.

Copyright: (c) 2021 by the authors. Licensee MDPI, Basel, Switzerland. This article is an open access article distributed under the terms and conditions of the Creative Commons Attribution (CC BY) license (https:// creativecommons.org/licenses/by/ $4.0 /)$.
Abstract: Calcareous sand, as a blow-fill or construction material, is widely used in island and reef construction projects in marine environments after treatment. When microorganism-induced mineralization is used to strengthen calcareous sand, salinity and other conditions in the marine environment will adversely affect microorganisms or their mineralization process. For this reason, the two environmental conditions created by deionized water and simulated seawater were introduced to explore their effects on the growth and urease activity of Sporosarcina pasteurii. Then, the changes in the permeability and mechanical strength of calcareous sand under different mineralization methods were compared by one-dimensional sand column tests. Finally, the reinforcement mechanism was compared and analyzed based on the results of scanning electron microscopy and X-ray diffraction tests. The results show that Sporosarcina pasteurii can induce carbonate and phosphate precipitation and mineralization to strengthen calcareous sand in simulated seawater. The mineralized products greatly reduce the permeability of calcareous sand and significantly improve the mechanical strength by wrapping calcareous sand particles, filling water seepage channels and cementing adjacent particles. The reinforcement effect of carbonate mineralization is better than that of phosphate mineralization, but phosphate mineralization has less impact on the environment during the treatment process.

Keywords: calcareous sand; microbial mineralization; Sporosarcina pasteurii; carbonate precipitation; phosphate precipitation

\section{Introduction}

Soil improvement is one of the most important issues in geotechnical engineering. Cement-based materials are widely used in various soil improvement. However, nearly $5-7 \%$ of global carbon dioxide emissions come from the cement industry [1], and the global carbon dioxide emissions rate is on the rise, causing serious harm to the environment. Microbial-induced biomineralization is a new sustainable soil improvement technology that can be a substitute for cement-based materials, especially for emerging economies with rapid infrastructure development [2]. Use of agricultural urease to induce carbonate precipitation (referred to herein as EICP, or Enzyme Induced Carbonate Precipitation) can also be used for soil improvement [3]. The very small size of the urease enzyme sub-unit (on the order of $12 \mathrm{~nm}$ ) suggests that EICP can penetrate finer grained soils and may be less susceptible to bio-plugging than microbial-induced biomineralization. However, the disadvantage of EICP is that nucleation points for precipitation provided by the microbes in biomineralization are not present [4].

Microbial-induced biomineralization mainly means that microorganisms change the surrounding environmental conditions through their own life activities, thereby controlling 
the formation and crystallization shape and size of minerals to achieve specific functions of mineralization. In nature, microorganisms are widely distributed and have the ability to induce the deposition of carbonate, phosphate, sulfate and other minerals [5-8]. In recent years, microbial mineralization has achieved good results in material improvement, concrete self-repair, ancient building protection and other fields [9-12]. The field of biomineralization includes a multidisciplinary research involving experts from various fields. However, several efforts need to be made to address key research and development questions necessary for commercial scale applications. Successful commercialization of the technique requires economical alternatives of the medium ingredients that cost as high as $60 \%$ of the total operating costs. Fortunately, use of inexpensive materials as corn steep liquor (CSL) or lactose mother liquor (LML) may help to lower the cost of treatment $[13,14]$.

At present, the widely studied microbial mineralization process is mainly based on urea hydrolysis. Urease-producing microorganisms hydrolyze urea to produce carbonate ions and ammonium ions, maintain the alkaline environment needed for most microbial mineralization, and finally achieve biomineralization [6]. Therefore, in the selection of microorganisms, it is necessary to select microorganisms rich in urease and decomposable urea and fully evaluate the effect of the application environment on the microbial growth and urease activity. The selection of the composition and concentration of a mineralization solution is directly related to the type and quantity of mineralization products, which need to ensure good mineralization effects and environmental friendliness. Currently, carbonate and phosphate mineralization products are the main types of available mineralization products.

There are many factors that affect microbial mineralization, in addition to the influence of microorganisms and mineralization solution, but these factors are also related to the properties of the treated materials. Due to the different physical and chemical properties, such as the inherent composition and particle size distribution of the materials, there may be many differences in the mineralization effect of different treatment materials during mineralization treatment. A series of experimental results that use carbonate precipitation as the product of microbial mineralization show that sand more easily realizes mineralization and can effectively improve its mechanical strength [15], and the mineralization effect of clay is mainly reflected in the improvement in the water stability and strength after treatment $[16,17]$. The stability and strength of residual soil and shale soil in freeze-thaw areas are also enhanced after microbial mineralization treatment [18]. For silty soil, the use of crude urease collected after microbial pyrolysis for mineralization treatment is better than the use of live bacteria [19].

In addition to the study of carbonate microbial mineralization, the study of phosphate as a mineralization product has received increasing attention from scholars $[7,20,21]$. Unlike carbonate mineralization, phosphate mineralization mainly uses ammonium ions produced by hydrolysis of urea. In alkaline environments, hydrogen phosphate ions and magnesium ions are introduced to react together to form magnesium ammonium phosphate and magnesium phosphate precipitates as mineralization products to improve the mechanical properties of the treated materials. Phosphate mineralization requires the participation of ammonium ions, which eliminates the potential environmental impact of ammonium ions to a certain extent, so it is more environmentally friendly.

Calcareous sand is a kind of engineering soil with calcium carbonate as the main composition, and it is widely distributed in many marine environments. It has poor mechanical properties, is easy to break and has high compressibility. Therefore, it is not suitable for direct use as a foundation, and it must be strengthened. For the mineralization treatment of the same material, the reinforcement effect, application conditions and environmental factors are considered, and it is very important to choose the appropriate microbial mineralization method, so it is necessary to compare the effects of different microbial mineralization treatments. In view of this, under the conditions of deionized water and simulated seawater, the effect of carbonate and phosphate precipitation mineral- 
ization induced by Sporosarcina pasteurii in strengthening calcareous sand is experimentally compared and evaluated.

\section{Materials and Methods}

\subsection{Physical Properties of Calcareous Sand}

The calcareous sand used in the experiment is taken from an island and reef in the South China Sea, which is mainly composed of calcium carbonate and mixed with a small amount of remains of marine life, such as shells and corals.

The permeability coefficient of calcareous sand is $1.001 \times 10^{-2} \mathrm{~cm} / \mathrm{s}$. Figure 1 shows the particle gradation curve of calcareous sand. The nonuniformity coefficient of calcareous sand is $\mathrm{Cu}=2.07$, and the curvature coefficient of $\mathrm{Cc}=0.92$ indicates poor gradation.

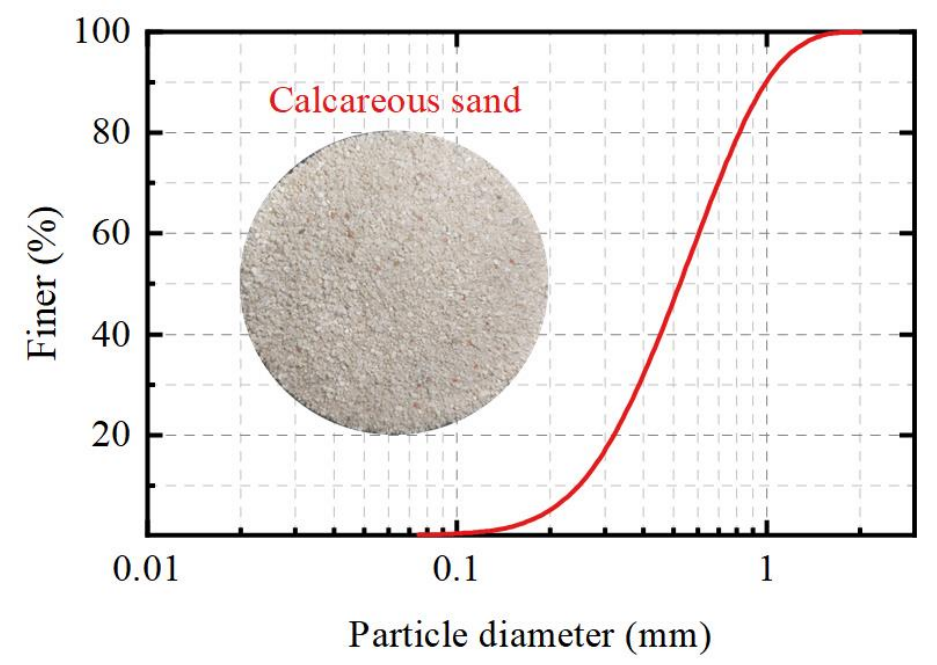

Figure 1. Particle size distribution curve of calcareous sand.

\subsection{Strains and Medium}

The microorganism selected in this experiment was Sporosarcina pasteurii, purchased from the German strain Preservation Center, and numbered DSM33. Sporosarcina pasteurii belongs to aerobic gram-positive bacteria, which are nonpathogenic and environmentally friendly. It is one of the bacteria with the highest urease activity and can produce a large amount of urease-decomposing urea [22]. Sporosarcina pasteurii was cultured in ATCC1376 $\mathrm{NH}_{4}$-YE medium. Since calcareous sand is mainly distributed in marine environments, the average salinity of seawater is approximately $3.5 \%$, which belongs to a high salinity environment. Therefore, a sodium chloride content of $0.6 \mathrm{~mol} / \mathrm{L}$ is added to the culture medium to simulate simulated seawater conditions and to promote the growth and urease activity of Sporosarcina pasteurii in a simulated seawater environment. In this experiment, deionized water was used to configure the culture medium and mineralized solution. The drugs were analytically pure.

\subsection{Number of Microorganisms and Urease Activity}

Sporosarcina pasteurii was cultured in a constant temperature oscillating chamber at a temperature of $30^{\circ} \mathrm{C}$ and a concussion frequency of $200 \mathrm{rpm}$. The growth number of bacteria can be expressed by the absorbance of the bacterial solution at a specific wavelength. The $\mathrm{OD}_{600}$ value of the culture solution was measured by a $754 \mathrm{UV}$-vis spectrophotometer produced by Shanghai Jinghua Science and Technology Instrument Co., Ltd. at a wavelength of $600 \mathrm{~nm}$, and blank medium was used as the control. Urease activity (UA) was determined according to the amount of urea decomposed by bacteria in a unit time. When urea is decomposed into carbonate ions and ammonium ions, the electrical conductivity (EC) of the solution will change, and the amount of urea decomposition can be calculated according to the change in the EC. In total, $3 \mathrm{~mL}$ of the bacterial solution to be tested was 
added to $27 \mathrm{~mL}$ of $1.5 \mathrm{~mol} / \mathrm{L}$ urea solution, the change in electrical conductivity in $8 \mathrm{~min}$ in the solution was measured, and the urease activity was calculated from Equation (1):

$$
U A=\frac{E C_{9 \min }-E C_{1 \min }}{8} \times 10 \times 11.11,
$$

Among them, the unit of UA is $\mathrm{mM}$ urea/min, the coefficient of 10 is the dilution multiple of the sample, and the coefficient of 11 represents the relationship between the change in the EC and the concentration of hydrolyzed urea [23].

\subsection{Composition and Concentration of Mineralized Solution}

Due to the different mineralization products, the composition and ratio of carbonate mineralization solution and phosphate mineralization solution are also different. The carbonate mineralization solution contains urea and calcium chloride with a concentration of $1 \mathrm{~mol} / \mathrm{L}$ and sodium chloride of $0.6 \mathrm{~mol} / \mathrm{L}$. In the process of mineralization, urea is decomposed by urease produced by Sporosarcina pasteurii to produce carbonate ions and react with the introduced calcium ions to form calcium carbonate precipitates. The main reactions are given in Equations (2) and (3):

$$
\begin{gathered}
\left(\mathrm{NH}_{2}\right)_{2} \mathrm{CO}+2 \mathrm{H}_{2} \mathrm{O} \stackrel{\text { urease }}{\longrightarrow} 2 \mathrm{NH}_{4}^{+}+\mathrm{CO}_{3}^{2-} \\
\mathrm{CO}_{3}^{2-}+\mathrm{Ca}^{2+} \rightarrow \mathrm{CaCO}_{3} \downarrow .
\end{gathered}
$$

The effective components in phosphate mineralization solution are urea, magnesium chloride and dipotassium hydrogen phosphate. However, in the process of phosphate mineralization, the production of magnesium ammonium phosphate is affected by the proportion and content of $\mathrm{pH}$, ammonium, phosphorus, magnesium and other factors, and other byproducts will appear. In a theoretical case, reactions such as those in Equations (2) and (4) will occur:

$$
\mathrm{NH}_{4}^{+}+\mathrm{HPO}_{4}^{2-}+\mathrm{Mg}^{2+}+6 \mathrm{H}_{2} \mathrm{O} \rightarrow \mathrm{MgNH}_{4} \mathrm{PO}_{4} \cdot 6 \mathrm{H}_{2} \mathrm{O}+\mathrm{H}^{+}
$$

However, in practice, the reactions in (5), (6) and (7) may also occur:

$$
\begin{gathered}
\mathrm{CO}_{3}^{2-}+\mathrm{Mg}^{2+}+3 \mathrm{H}_{2} \mathrm{O} \rightarrow \mathrm{MgCO}_{3} \cdot\left(\mathrm{H}_{2} \mathrm{O}\right)_{3} \downarrow \\
\mathrm{CO}_{3}^{2-}+\mathrm{Mg}^{2+}+2 \mathrm{H}_{2} \mathrm{O} \rightarrow \mathrm{MgCO}_{3} \cdot 2 \mathrm{H}_{2} \mathrm{O} \downarrow \\
\mathrm{HPO}_{4}^{2-}+\mathrm{Mg}^{2+}+3 \mathrm{H}_{2} \mathrm{O} \rightarrow \mathrm{MgHPO}_{4} \cdot\left(\mathrm{H}_{2} \mathrm{O}\right)_{3} \downarrow .
\end{gathered}
$$

The formation of byproducts will affect the yield of magnesium ammonium phosphate, the main mineralization product and affect the recovery and utilization of ammonium ions. Therefore, it is necessary to increase the yield of magnesium ammonium phosphate as much as possible. In previous studies, when the ratio of urea:magnesium chloride:dipotassium hydrogen phosphate was 1:2:2, the yield of magnesium ammonium phosphate was higher $[7,20]$. Therefore, in this experiment, the phosphate mineralization solution contained $1 \mathrm{~mol} / \mathrm{L}$ of urea, $2 \mathrm{~mol} / \mathrm{L}$ of magnesium chloride, $2 \mathrm{~mol} / \mathrm{L}$ dipotassium hydrogen phosphate and $0.6 \mathrm{~mol} / \mathrm{L}$ of sodium chloride.

\subsection{Mineralization Treatment Mode and Scheme Setting}

Peristaltic pump grouting was used to inject bacterial liquid and two kinds of mineralized solutions into calcareous sand columns from bottom to top by, and the changes in permeability and unconfined compressive (UCS) strength of calcareous sand before and after treatment were studied. The microscopic shape and composition of mineralized products were analyzed by SEM and XRD. 


\subsubsection{Test Mold and Device}

A schematic diagram of the grouting process of the peristaltic pump is shown in Figure 2. In the test, a PVC pipe with an inner diameter of $3.5 \mathrm{~cm}$ and height of $8.0 \mathrm{~cm}$ was used as the sand column mold. The homogenized calcareous sand was filled in three layers, vibrated and compacted, and the mass of the sand column was controlled to be $105 \pm 1 \mathrm{~g}$, the initial void ratio is about $45.35 \%$. After filling, a 160 mesh round nylon filter with a diameter of $3.5 \mathrm{~cm}$ was placed at the end of the sand column to prevent the loss of sand particles. The pipe caps at both ends and the sand column were fixed with a fixed bracket to ensure that the volume of the sand column was constant in the process of grouting reinforcement. Before the bracket was fixed, a silicone gasket was placed in the pipe cap to prevent liquid leakage during the process of grouting. To avoid the occurrence of a gas cavity in the process of grouting and prevent the grouting fluid from filling the whole sand column unevenly, the sand column was vacuum saturated before grouting mineralization, and the filled sand column was fixed in the saturator and put into the vacuum cylinder. Vacuum saturation occurred through the suction machine.

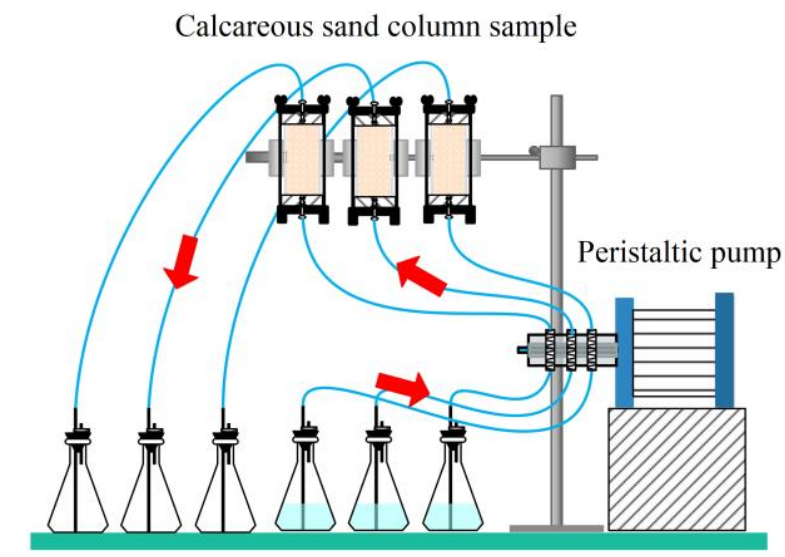

Waste liquid collection Grouting solution

Figure 2. Schematic diagram of calcareous sand reinforced by peristaltic pump grouting.

\subsubsection{Grouting Scheme Setting}

A solution of Sporosarcina pasteurii cultured in the stable phase for $48 \mathrm{~h}$ was used in the two mineralization schemes, and the $\mathrm{OD}_{600}$ value was approximately 1.6. For the carbonate mineralization scheme, at the beginning of the daily mineralization treatment, the bacterial solution of $50 \mathrm{~mL}$ (approximately 1.5 times pore volume) was injected first, and the peristaltic pump was injected at a speed of $1 \mathrm{~mL} / \mathrm{min}$. Then, the same volume of $1 \mathrm{~mol} / \mathrm{L}$ urea and the mixed solution of calcium chloride and $0.6 \mathrm{~mol} / \mathrm{L}$ of sodium chloride were injected at an interval of $6 \mathrm{~h}$ to complete the mineralization treatment. The mineralization treatment time was $5 \mathrm{~d}$, and after the mineralization was complete, it was left static for $2 \mathrm{~d}$ until the follow-up test.

To ensure the mineralization effect of the phosphate mineralization scheme, the grouting process is divided into two steps. Liquid A $(50 \mathrm{~mL}$, containing bacterial solution, $2 \mathrm{~mol} / \mathrm{L}$ of dipotassium hydrogen phosphate and $0.6 \mathrm{~mol} / \mathrm{L}$ of sodium chloride) was injected first, and then liquid B $(50 \mathrm{~mL}, 1 \mathrm{~mol} / \mathrm{L}$ of urea containing, $2 \mathrm{~mol} / \mathrm{L}$ of magnesium chloride and $0.6 \mathrm{~mol} / \mathrm{L}$ of sodium chloride) was injected $6 \mathrm{~h}$ later. The mineralization treatment time was $5 \mathrm{~d}$, and the sample was tested after standing for $2 \mathrm{~d}$.

\subsection{Evaluation of the Mineralization Effect \\ 2.6.1. Permeability Test}

For calcareous sand columns treated with different mineralization schemes, deionized water was used for washing to remove salt and residual organic matter and then the permeability coefficients of calcareous sand treated with different mineralization schemes were tested and compared with that of undisturbed calcareous sand. 


\subsubsection{UCS Test}

After the permeability test, the sand column was dried, and the UCS test was performed. The UCS test of the sand column was determined via a modified TSZ-3 strain control triaxial apparatus produced by Nanjing Soil Instrument Factory Co., Ltd. (Nanjing, China), and the loading rate was $1.0 \mathrm{~mm} / \mathrm{min}$ until the sample was destroyed.

\subsubsection{SEM Test}

After the UCS test, the samples were collected and treated with gold spray, and their micromorphology and structure were observed under a scanning electron microscope. The SEM test equipment was a built-in energy spectrometer bench scanning electron microscope produced by Phenom-Word BV Company in the Netherlands (Phenom proX), and the acceleration voltage of the test reached $15 \mathrm{kV}$.

\subsubsection{XRD Test}

In addition, some of the fully ground samples were tested by XRD, and the composition and crystal form of the mineralized products were analyzed. The equipment used in the XRD test was SmartLab, which was produced by Nippon Co., Ltd. (Tokyo, Japan), and the working voltage of the sample was $40 \mathrm{kV}$ and the current was $30 \mathrm{~mA}$. The starting angle of XRD test parameter $2 \theta$ was set to $5^{\circ}$, the end angle was set to $60^{\circ}$ and the step size was set to 0.02 .

\section{Results and Discussion}

\subsection{Growth and Urease Activity of Microorganisms}

\subsubsection{Growth of Sporosarcina pasteurii}

Figure 3 shows the growth curve of Sporosarcina pasteurii under fresh water and simulated seawater conditions. The growth of Sporosarcina pasteurii was inhibited to a certain extent in the saline environment with $0.6 \mathrm{~mol} / \mathrm{L}$ sodium chloride, and the growth of bacteria appeared to be a small lag phase. In the logarithmic phase of approximately $24 \mathrm{~h}$, the $\mathrm{OD}_{600}$ value was smaller than that of culture without sodium chloride. After $24 \mathrm{~h}$, the $\mathrm{OD}_{600}$ values of bacteria in the two environments were similar, and the $\mathrm{OD}_{600}$ values of bacteria in the stable period of $48 \mathrm{~h}$ showed almost no difference.

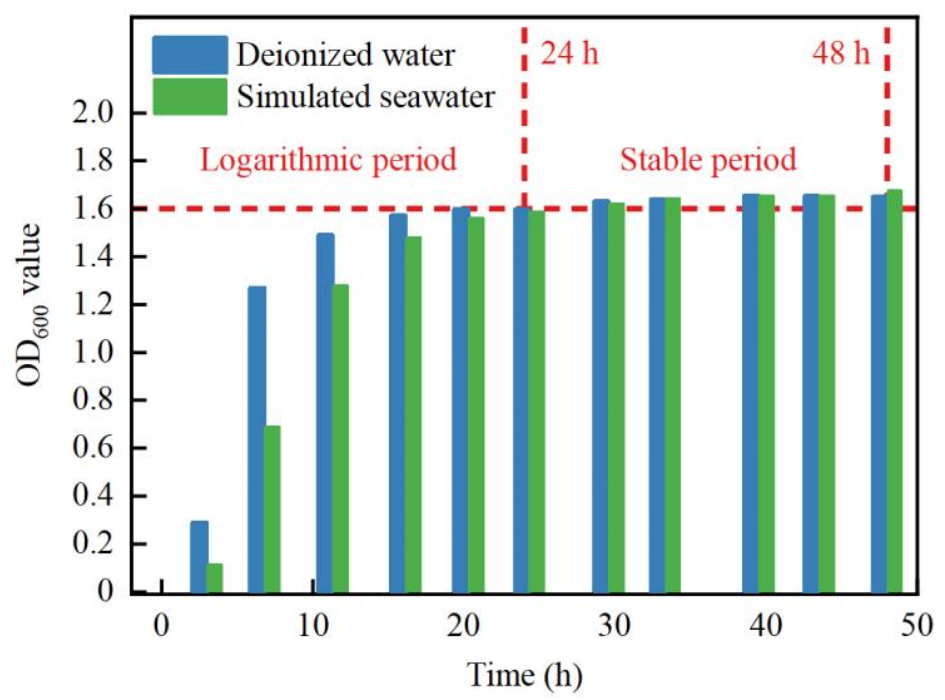

Figure 3. Growth curve of Sporosarcina pasteurii under different conditions.

In the simulated seawater environment, due to the increase in osmotic pressure and ionic strength, the number of bacteria in the logarithmic phase was lower and there was a lag compared with normal growth, so simulated seawater had an adverse effect on Sporosarcina pasteurii. However, after $24 \mathrm{~h}$, in the stable period of bacterial culture, the 
inhibition was basically lifted, especially in the harvest period of Pasteurella multocida in $48 \mathrm{~h}$, and the $\mathrm{OD}_{600}$ value of Sporosarcina pasteurii cultured in simulated seawater was even slightly higher than that under normal conditions. This shows that Sporosarcina pasteurii can adapt to this kind of simulated seawater environment, can grow and reproduce normally, and can be used as a candidate bacteria for microbial mineralization under simulated seawater conditions.

\subsubsection{Urease Activity of Sporosarcina pasteurii}

Figure 4 shows the variation curve of urease activity of Sporosarcina pasteurii with time under the fresh water and simulated seawater conditions. During the whole culture period, the urease activity of sodium chloride supplemented with $0.6 \mathrm{~mol} / \mathrm{L}$ was always lower than that of Sporosarcina pasteurii cultured in deionized water. At a harvest time of $48 \mathrm{~h}$, the urease activity of the bacterial liquid in the two groups tended to be stable and reached the maximum value.

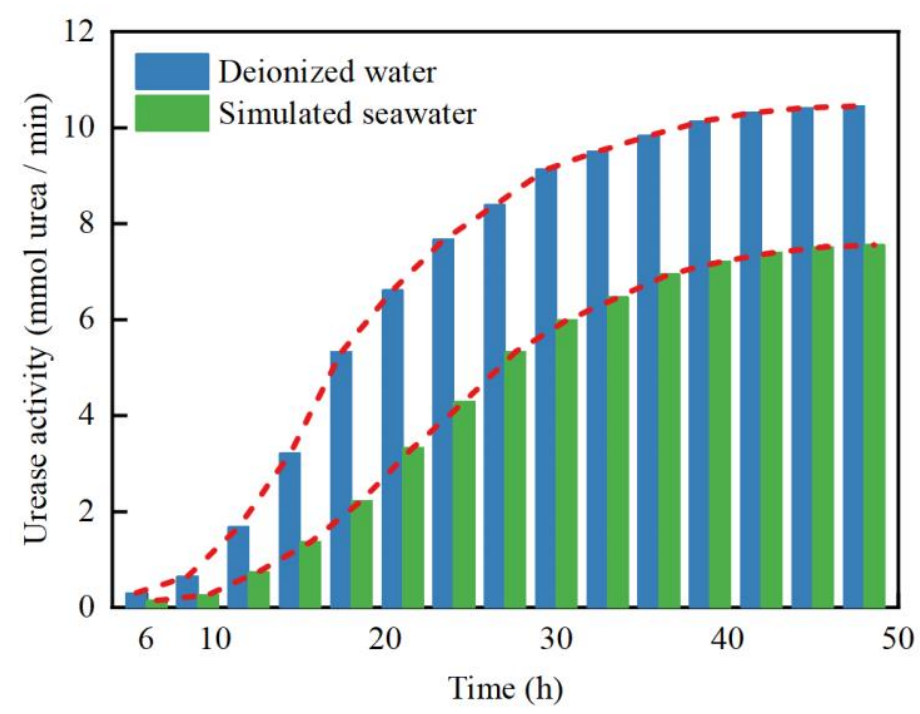

Figure 4. Effects of different growth environments on urease activity.

The salinity of seawater can inhibit the urease activity of Sporosarcina pasteurii. Compared with the changes in its growth quantity, it can be found that although the salinity condition of seawater has little effect on the final number of Sporosarcina pasteurii, it has a great influence on urease activity. Usually, because the cell membrane itself belongs to the osmotic membrane, when the concentration of sodium chloride is high, it will exhibit a concentration difference compared to the cytoplasm of microorganisms, thereby resulting in water extravasation within microorganisms, causing cell dehydration, and reducing the activity of intracellular enzymes [21].

Generally, under simulated seawater conditions, Sporosarcina pasteurii can grow, reproduce normally and retain most of the urease activity. There is evidence that Sporosarcina pasteurii can grow at salinities equal to $100 \%$ sea water [24], and Sporosarcina pasteurii can effectively induce mineralization under the condition of simulated seawater and is suitable to be used as a dominant strain for the treatment of calcareous sand by microbial mineralization.

\subsection{Permeability Test Results and Analysis}

After different mineralization treatments, the permeability of the washed sand column was tested and compared with that of undisturbed calcareous sand. The results are shown in Figure 5. The permeability coefficient of calcareous sand after carbonate mineralization and phosphate mineralization is significantly lower than that of undisturbed calcareous sand, which can be reduced by an order of magnitude. In comparison, regardless of the 
condition of deionized water or simulated seawater, the effect of carbonate mineralization on the permeability is more obvious, and the permeability coefficient of calcareous sand decreases more after treatment. For the two mineralization methods, after the addition of $0.6 \mathrm{~mol} / \mathrm{L}$ of sodium chloride, the effect of mineralization treatment on the permeability of calcareous sand is weakened, but it is still much lower than that of the nontreatment condition, which fully shows that the two mineralization methods can obviously change the permeability of calcareous sand after treatment, and the effect of carbonate mineralization is more obvious.

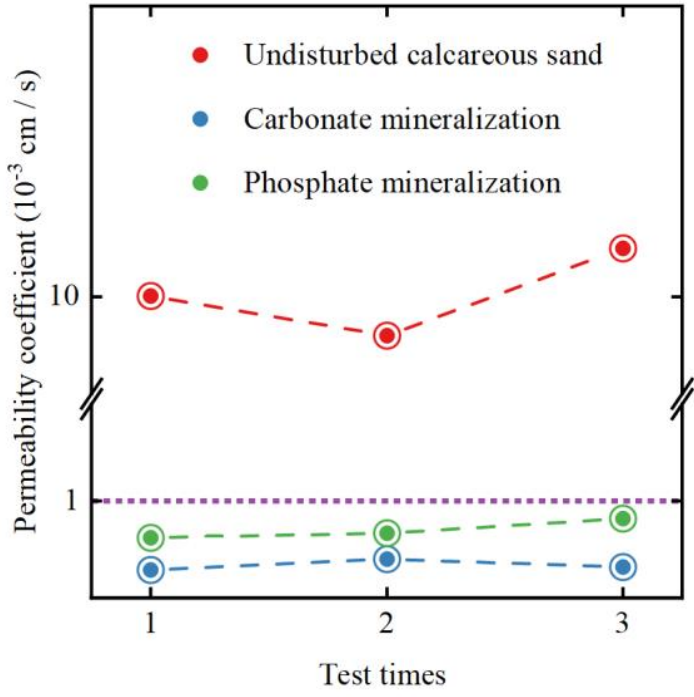

(a) Deionized water

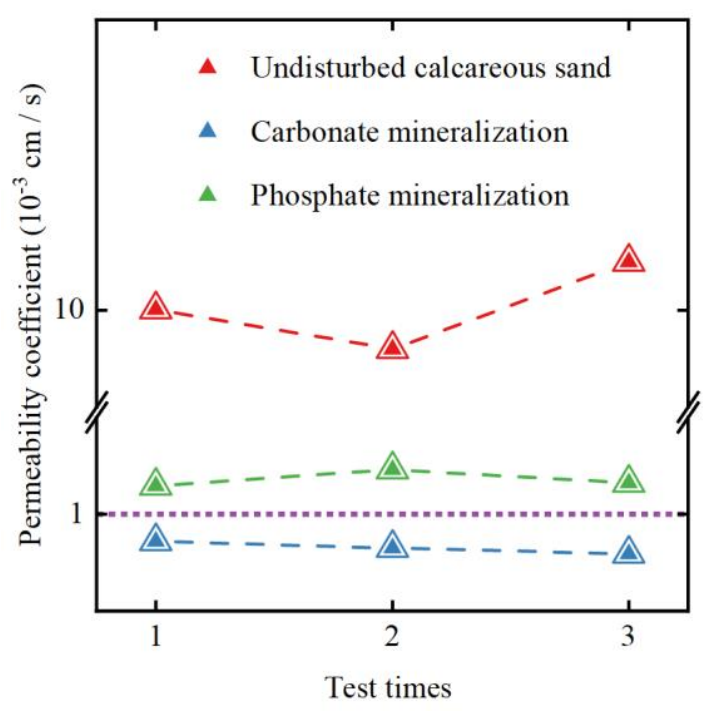

(b) Simulated seawater

Figure 5. Effect of mineralization treatment on the permeability of calcareous sand in different environments. (a) Deionized water (b) Simulated seawater.

There are many pores in the undisturbed calcareous sand, such as the inner pores of calcareous sand particles and the pores between particles. Therefore, before treatment, the permeability coefficient and permeability are higher than those after treatment. After mineralization, due to the formation, precipitation and accumulation of carbonate and phosphate mineralized products, the pores will be plugged, and the seepage channel will be blocked or partially closed, thereby resulting in a significant decrease in permeability. The comparison of the changes in permeability shows that carbonate biomineralization reduces the permeability of calcareous sand, thereby indicating that carbonate mineralization products fill more pores. This may be because the calcareous sand itself is mainly composed of calcium carbonate, which has better compatibility with the newly formed carbonate mineralization products, resulting in a more obvious decrease in its permeability. Salinity has an adverse effect on mineralization, and under this unfavorable condition, the permeability of calcareous sand treated by phosphate mineralization is more affected. This may be due to the existence of salinity; the stacking structure of phosphate mineralization products will change and then affect the pore filling efficiency, so the mineralization effect will experience a greater affect.

\subsection{UCS Test Results and Analysis}

The results of the UCS test are shown in Figure 6. After mineralization treatment, the mechanical strength of calcareous sand is obviously improved, and the average UCS strength is higher than $1 \mathrm{MPa}$. In comparison, the strength of UCS after carbonate mineralization is higher, while that of UCS after phosphate mineralization is slightly lower, which corresponds to the change in permeability. As the carbonate mineralization products fill more pores, it is not easy for calcareous sand particles to move relatively to each 
other after experiencing stress. Especially after mineralization, the original loose sand cementation as a whole greatly improves the mechanical strength. The effect of salinity on the UCS strength is similar to its effect on permeability. After adding sodium chloride, the UCS strength of the calcareous sand column decreases to varying degrees, while the UCS strength of calcareous sand treated with phosphate mineralization decreases more. As the reaction in the process of phosphate mineralization is more complex and affected by a variety of regulatory factors, the mineralization effect may be more sensitive to the existence of adverse effects.

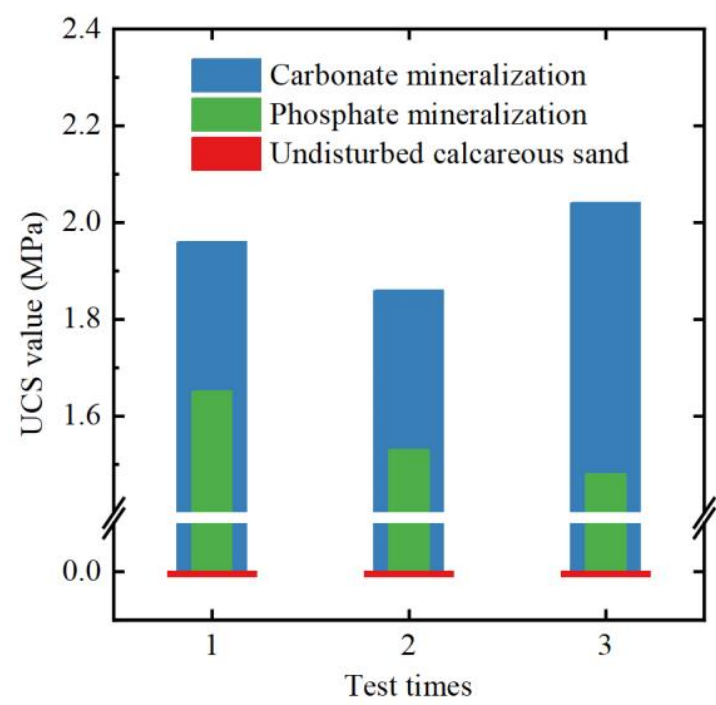

(a) Deionized water

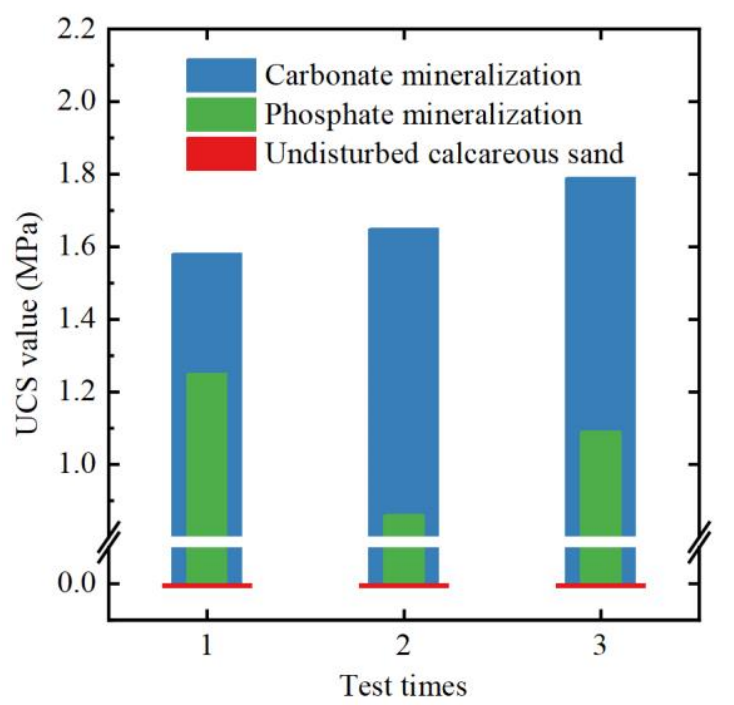

(b) Simulated seawater

Figure 6. Effect of mineralization treatment on the UCS strength of calcareous sand in different environments. (a) Deionized water. (b) Simulated seawater.

Generally, the effect of carbonate mineralization is better than that of phosphate mineralization, the permeability decreases more and the UCS strength is higher. As an unfavorable factor in mineralization treatment, simulated seawater has a substantial influence on phosphate mineralization. However, from the point of view of environmental protection, phosphate mineralization treatment obviously has more advantages because of the consumption of ammonium ions, and the permeability and UCS value of calcareous sand are significantly improved compared with those of undisturbed calcareous sand, which can meet the needs of general engineering.

\subsection{SEM Test Results}

The results of the SEM test are shown in Figure 7. Figure 7a,b show that after carbonate mineralization, the surface of calcareous sand mineralized under the condition of deionized water is covered with a layer of dense carbonate products, which should be calcium carbonate according to the test conditions. Calcium carbonate wraps the calcareous sand particles, fills the intergranular pores and causes the sand particles to be cemented together, which finally reduces the permeability of calcareous sand and improves its mechanical strength. Although the calcareous sand mineralized under the condition of simulated seawater also produces calcium carbonate between grains, due to the adverse effect of salinity, the amount of calcium carbonate is low, so its mineralization effect is weakened to a certain extent. 


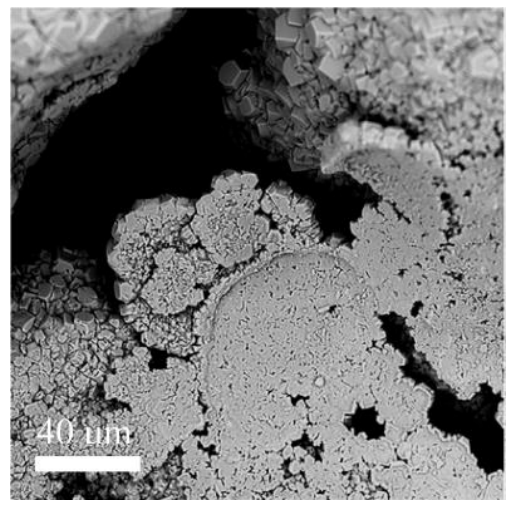

(a) Carbonate mineralization in deionized water

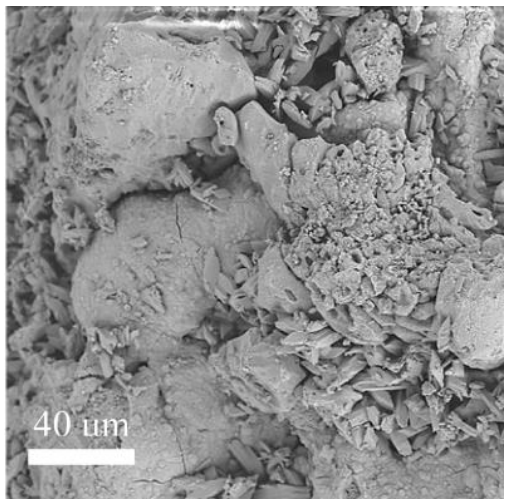

(c) Phosphate mineralization in deionized water

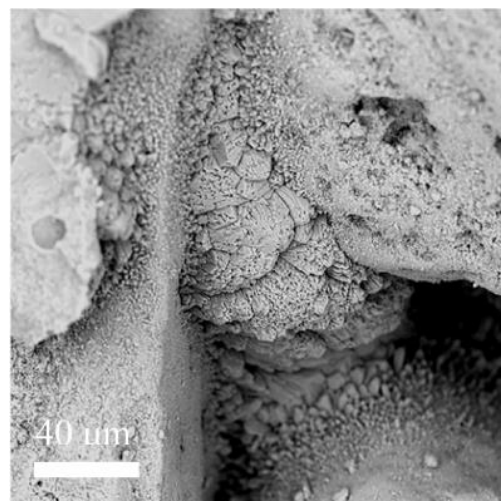

(b) Carbonate mineralization in simulated seawater

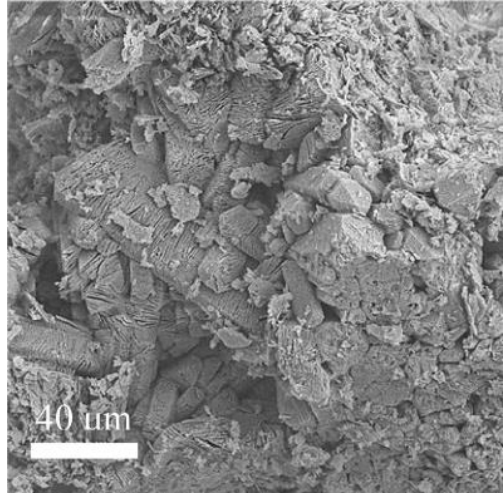

(d) Phosphate mineralization in simulated seawater

Figure 7. SEM images of calcareous sand after different mineralization treatments. (a) Carbonate mineralization in deionized water. (b) Carbonate mineralization in simulated seawater. (c) Phosphate mineralization in deionized water. (d) Phosphate mineralization in simulated seawater.

Figure 7c,d shows that after phosphate mineralization, under the condition of deionized water, the main phosphate mineralization product is an obliquely long column, which is speculated to be magnesium ammonium phosphate, and there are some irregular cluster-like substances, which may be byproducts. The phosphate mineralization products accumulate in the pores between particles and are cemented to the surface of calcareous sand particles; under the condition of simulated seawater, the morphology of long columnar magnesium ammonium phosphate changes obviously, and the oblique column of magnesium ammonium phosphate is mainly formed by lamellar crystal stacking. There are obvious pores between flake crystals, and there are a large number of irregular mineralization products in the figure. In recent studies, it has been found that salinity has an effect on the stacking structure of magnesium ammonium phosphate; this causes the crystal shape to change from a long column to a flake [21], which is consistent with the results of this experiment. The lamellar accumulation retains some pores, and the seepage channel is retained, so it easily moves and compresses under stress and the mineralization effect is lower than that under deionized water.

In comparison, the mineral crystal packing density and size of carbonate are better than those of phosphate mineralization, so the mineralization effect is better, the permeability decreases more and the UCS strength is higher.

\subsection{XRD Test Results}

After washing and drying, the samples were fully ground, and the composition of the XRD test was analyzed. Figure $8 \mathrm{a}, \mathrm{b}$ shows the XRD test results of the samples after carbonate mineralization, and Figure $9 a, b$ gives the XRD test results of the samples after phosphate mineralization. 


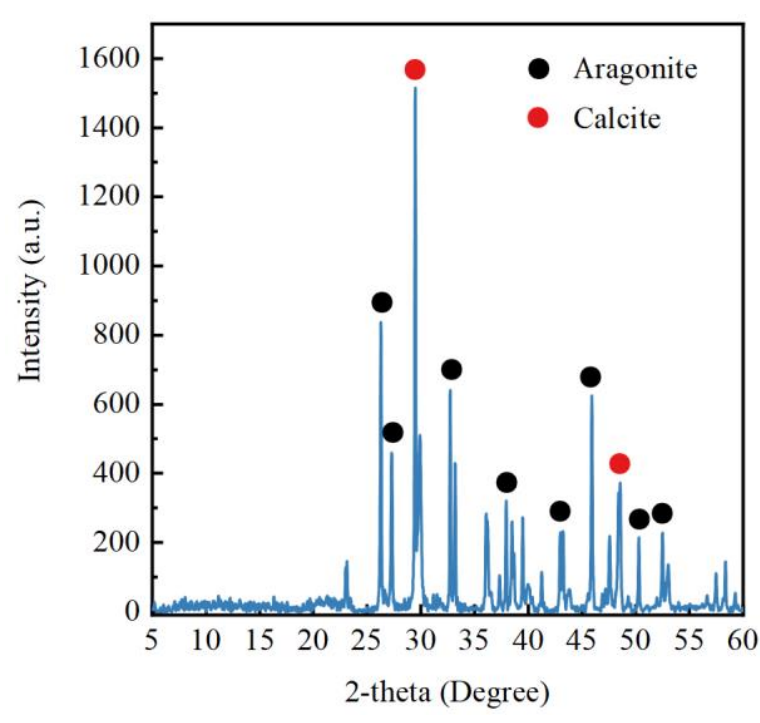

(a) Deionized water

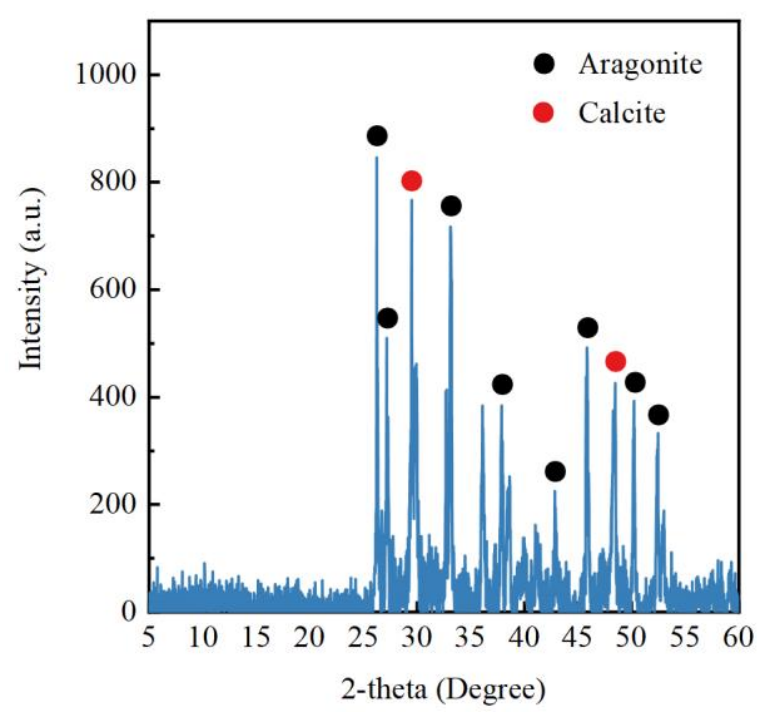

(b) Simulated seawater

Figure 8. XRD analysis of carbonate mineralization products in different environments. (b) Simulated seawater.

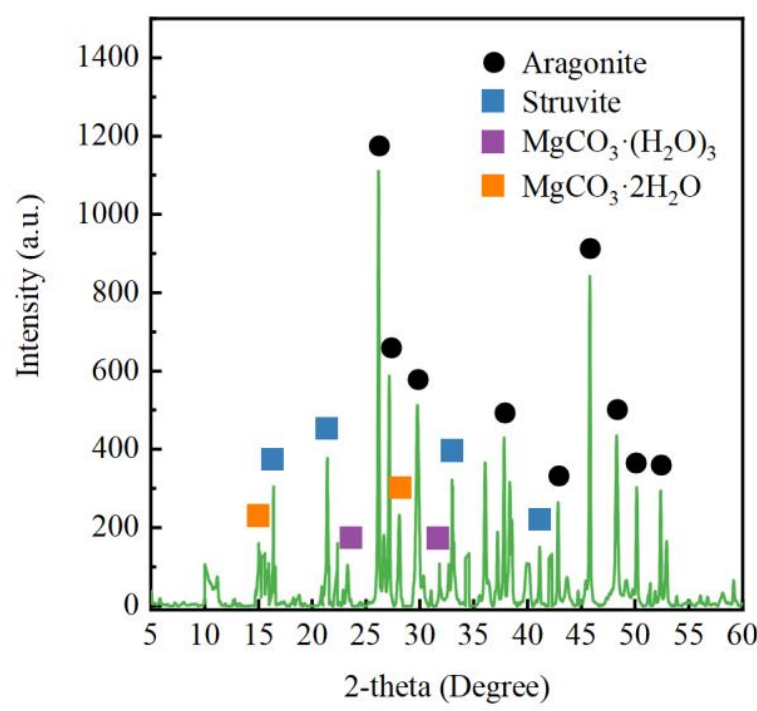

(a) Deionized water

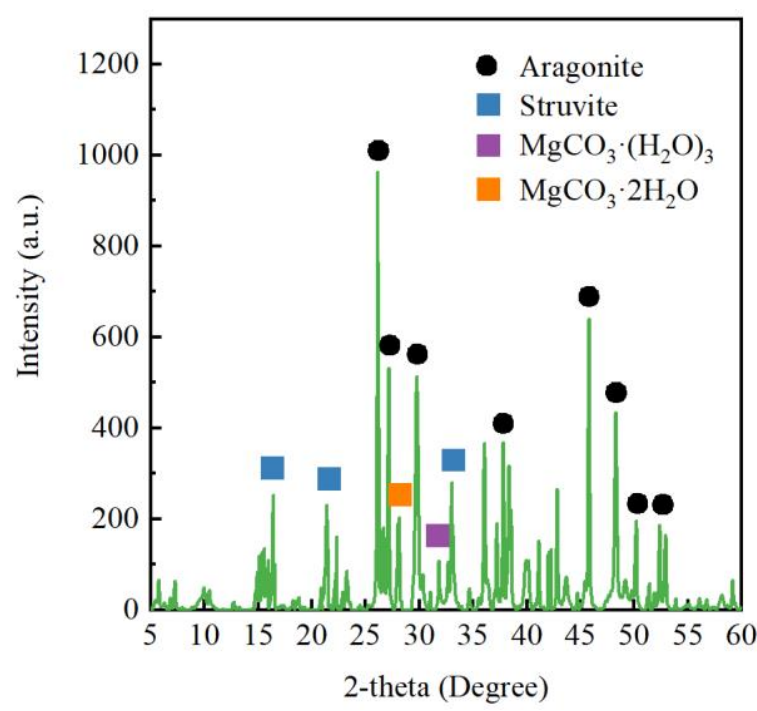

(b) Simulated seawater

Figure 9. XRD analysis of phosphate mineralization products in different environments.

(a) Deionized water.

(b) Simulated seawater.

For the calcareous sand after carbonate mineralization, the XRD results show that the newly formed carbonate mineralization product is calcium carbonate and that the crystal form is calcite, which is different from the inherent crystal type of calcium carbonate (aragonite). Calcite is the most stable crystal form of calcium carbonate in a natural state, and its mechanical properties are good, so calcite improves the mechanical strength of calcareous sand [25]. For calcareous sand after phosphate mineralization, the main mineralized product is magnesium ammonium phosphate hexahydrate, but due to the occurrence of side reactions, there are small amounts of magnesium carbonate dihydrate and trihydrate, which are amorphous minerals in the SEM diagram. 


\section{Conclusions}

In this paper, the effects of mineralization treatment of calcareous sand with different mineralization products were compared. The main conclusions are as follows: (1) Sporosarcina pasteurii can induce mineralization under simulated seawater conditions. After microbial mineralization of calcareous sand with carbonate mineralization products and phosphate mineralization products, the permeability of calcareous sand decreases significantly, and the UCS strength increases obviously. Among them, the effect of carbonate mineralization is better than that of phosphate mineralization. (2) The main product of carbonate mineralization is calcium carbonate, and the crystal form is calcite; the main component of the phosphate mineralization product is magnesium ammonium phosphate hexahydrate, and the dihydrate and trihydrate of magnesium carbonate are also formed in the process of mineralization. (3) Although the effect of phosphate mineralization is slightly weaker than that of carbonate mineralization, the method itself is more environmentally friendly, and the mineralization effect can meet the needs of general engineering, so it has great application potential.

Author Contributions: Conceptualization, S.L.; methodology, B.D.; software, B.D.; validation, formal analysis, investigation, B.D.; writing-review and editing, J.Y.; writing-review and editing, Y.C.; writing-review and editing, X.P.; writing-review and editing, X.Z. All authors have read and agreed to the published version of the manuscript.

Funding: This research was funded by the Natural Science Foundation of Fujian Province (No. 2019J01048), the Scientific Research Foundation of Huaqiao University (No. 18BS309), and the Subsidized Project for Postgraduates' Innovative Fund in Scientific Research of Huaqiao University (No. 18014086010).

Institutional Review Board Statement: Not applicable.

Informed Consent Statement: Not applicable.

Data Availability Statement: Data is not publicly available, though the data may be made available on request from the corresponding author.

Acknowledgments: The authors are thankful for the financial support from the Natural Science Foundation of Fujian Province (No. 2019J01048), the Scientific Research Foundation of Huaqiao University (No. 18BS309), and the Subsidized Project for Postgraduates' Innovative Fund in Scientific Research of Huaqiao University (No. 18014086010).

Conflicts of Interest: The authors declare no conflict of interest.

\section{References}

1. Benhelal, E.; Zahedi, G.; Shamsaei, E.; Bahadori, A. Global strategies and potentials to curb $\mathrm{CO}_{2}$ emissions in cement industry. J. Clean. Prod. 2013, 51, 142-161. [CrossRef]

2. Mondal, S.; Ghosh, A. Microbial Concrete as a Sustainable Option for Infrastructural Development in Emerging Economies. ASCE India Conf. 2017, 413-423. [CrossRef]

3. Yasuhara, H.; Neupane, D.; Hayashi, K.; Okamura, M. Experiments and Predictions of Physical Properties of Sand Cemented by Enzymatically-induced Carbonate Precipitation. Soils Found. 2012, 52, 539-549. [CrossRef]

4. Kavazanjian, E.; Almajed, A.; Hamdan, N. Bio-inspired Soil Improvement using EICP Soil Columns and Soil Nails. Grouting 2017, 288, 13-22. [CrossRef]

5. Martinez, B.C.; DeJong, J.T.; Ginn, T.R.; Montoya, B.M.; Barkouki, T.H.; Hunt, C.; Tanyu, B.; Major, D. Experimental Optimization of Microbial-Induced Carbonate Precipitation for Soil Improvement. J. Geotech. Geoenviron. Eng. 2013, 139, 587-598. [CrossRef]

6. DeJong, J.T.; Mortensen, B.M.; Martinez, B.C.; Nelson, D.C. Bio-Mediated Soil Improvement. Ecol. Eng. 2010, 36, 197-210. [CrossRef]

7. Yu, X.; Qian, C.; Xue, B. Loose Sand Particles Cemented by Different Bio-Phosphate and Carbonate Composite Cement. Constr. Build. Mater. 2016, 113, 571-578. [CrossRef]

8. Pham, V.P.; van Paassen, L.A.; van der Star, W.R.L.; Heimovaara, T.J. Evaluating Strategies to Improve Process Efficiency of Denitrification-Based MICP. J. Geotech. Geoenviron. Eng. 2018, 144, 04018049. [CrossRef]

9. Xiao, Y.; Stuedlein, A.W.; Pan, Z.; Liu, H.; Matthew Evans, T.; He, X.; Lin, H.; Chu, J.; van Paassen, L.A. Toe-Bearing Capacity of Precast Concrete Piles through Biogrouting Improvement. J. Geotech. Geoenviron. Eng. 2020, 146, 06020026. [CrossRef] 
10. Luo, M.; Qian, C.; Li, R. Factors Affecting Crack Repairing Capacity of Bacteria-Based Self-Healing Concrete. Constr. Build. Mater. 2015, 87, 1-7. [CrossRef]

11. Choi, S.-G.; Wang, K.; Wen, Z.; Chu, J. Mortar Crack Repair Using Microbial Induced Calcite Precipitation Method. Cem. Concr. Compos. 2017, 83, 209-221. [CrossRef]

12. Liu, S.; Wang, R.; Yu, J.; Peng, X.; Cai, Y.; Tu, B. Effectiveness of the Anti-Erosion of an MICP Coating on the Surfaces of Ancient Clay Roof Tiles. Constr. Build. Mater. 2020, 243, 118202. [CrossRef]

13. Achal, V.; Mukherjee, A.; Reddy, M.S. Biocalcification by Sporosarcina pasteurii using Corn Steep Liquor as Nutrient Source. Ind. Biotechnol. 2010, 6, 170-174. [CrossRef]

14. Mitchell, A.C.; Dideriksen, K.; Spangler, L.; Cunningham, A.; Gerlach, R. Microbially Enhanced Carbon Capture and Storage by Mineral-trapping and Solubility-trapping. Environ. Sci. Technol. 2010, 44, 5270-5276. [CrossRef]

15. Xiao, P.; Liu, H.; Stuedlein, A.W.; Evans, T.M.; Xiao, Y. Effect of Relative Density and Biocementation on Cyclic Response of Calcareous Sand. Can. Geotech. J. 2019, 56, 1849-1862. [CrossRef]

16. Islam, M.T.; Chittoori, B.C.S.; Burbank, M. Evaluating the Applicability of Biostimulated Calcium Carbonate Precipitation to Stabilize Clayey Soils. J. Mater. Civ. Eng. 2020, 32, 04019369. [CrossRef]

17. Jiang, N.-J.; Soga, K.; Kuo, M. Microbially Induced Carbonate Precipitation for Seepage-Induced Internal Erosion Control in Sand-Clay Mixtures. J. Geotech. Geoenviron. Eng. 2017, 143, 04016100. [CrossRef]

18. Jin, G.; Xu, K.; Xu, C.; Huang, M.; Abdulwahab Qasem, R.G.; Guo, S.; Liu, S. Cementation of Shale Soils by MICP Technology and Its Damage Characteristics Due to Freeze-Thaw Weathering Processes. J. Cold Reg. Eng. 2020, 34, 04020023. [CrossRef]

19. He, J.; Gao, Y.; Gu, Z.; Chu, J.; Wang, L. Characterization of Crude Bacterial Urease for CaCO3 Precipitation and Cementation of Silty Sand. J. Mater. Civ. Eng. 2020, 32, 04020071. [CrossRef]

20. Yu, X.; Zhan, Q.; Qian, C.; Ma, J.; Liang, Y. The Optimal Formulation of Bio-Carbonate and Bio-Magnesium Phosphate Cement to Reduce Ammonia Emission. J. Clean. Prod. 2019, 240, 118156. [CrossRef]

21. Zhao, T.-L.; Li, H.; Huang, Y.-R.; Yao, Q.-Z.; Huang, Y.; Zhou, G.-T. Microbial Mineralization of Struvite: Salinity Effect and Its Implication for Phosphorus Removal and Recovery. Chem. Eng. J. 2019, 358, 1324-1331. [CrossRef]

22. Braissant, O.; Verrecchia, E.P.; Aragno, M. Is the Contribution of Bacteria to Terrestrial Carbon Budget Greatly Underestimated? Naturwissenschaften 2002, 89, 366-370. [CrossRef] [PubMed]

23. Wang, Y.-J.; Han, X.-L.; Jiang, N.-J.; Wang, J.; Feng, J. The Effect of Enrichment Media on the Stimulation of Native Ureolytic Bacteria in Calcareous Sand. Int. J. Environ. Sci. Technol. 2020, 17, 1795-1808. [CrossRef]

24. Mortensen, B.M.; Haber, M.J.; DeJong, J.T.; Caslake, L.F.; Nelson, D.C. Effects of Environmental Factors on Microbial Induced Calcium Carbonate Precipitation. J. Appl. Microbiol. 2011, 111, 338-349. [CrossRef]

25. Al Qabany, A.; Soga, K.; Santamarina, C. Factors Affecting Efficiency of Microbially Induced Calcite Precipitation. J. Geotech. Geoenviron. Eng. 2012, 138, 992-1001. [CrossRef] 